\title{
Breach Rate Analysis of Pedicle Screw Instrumentation using Free-Hand Technique in the Surgical Correction of Adolescent Idiopathic Scoliosis
}

\author{
Didik Librianto ${ }^{1}$, Ifran Saleh ${ }^{2}$, Fachrisal ${ }^{1}$, Widyastuti Srie Utami ${ }^{3}$, Witantra Dhamar Hutami ${ }^{2}$
}

Learning Point of the Article:

Free-hand technique is safe and effective method of pedicle screw instrumentation for correction of AIS, however care should be taken as some inherent factors may influence the risk of pedicle screw breach.

\section{Abstract}

Introduction: Free-hand technique is one of the techniques used by spine surgeon during pedicle screw instrumentation of surgical correction of spinal deformities, including scoliosis. The previous studies showed that this technique is safe. However, some inherent factors may influence its outcomes, including screw breaching which is potentially violates spinal cord and other intimate structures. To confirm the safety and accuracy of this technique, additional study measuring the breach rate of pedicle screw placement in scoliosis is mandatory.

Materials and Methods: We performed a retrospective study of patients with adolescent idiopathic scoliosis (AIS) from Fatmawati General Hospital, Jakarta, treated for surgical correction during a period of 2017-2018 using free-hand technique for pedicle screw instrumentation. Post-operative computed tomography scan (CT scan) was analyzed to measure the medial and lateral breaches. $\mathrm{P}<0.05$ was deemed to be statistically significant.

Results: A total of 94 pedicle screws from six female patients with AIS were included in our study. Overall breach occurred in $33 \%$ instrumented screws, the majority of it was a low-grade breach. Of the breached screws, medial and lateral breach occurred in $20 \%$ and $12 \%$ of screws, respectively. There were no differences in the overall, medial, and lateral breaches between thoracic and lumbar vertebrae $(\mathrm{P}>0.05)$. Medial breach was significantly higher in middle thoracic segment compared to other thoracic segments $(P=0.048)$. Risk of medial breach was 3 times higher in the convex side of deformity $(\mathrm{P}=0.012)$, whereas risk of lateral breach was 4.6 times higher in the concave side of the deformity $(\mathrm{P}=$ 0.021 ).

Conclusion: The majority of breached screws were low-grade violation within the safe zone, with no neurological sequelae. Our study found that free-hand technique is safe and effective method of pedicle screw instrumentation for correction of AIS. Some inherent factors may influence the risk of pedicle screw breach.

Keywords: Adolescent idiopathic scoliosis, pedicle screw instrumentation, free-hand technique, breach rate.

\section{Introduction}

For fusion of thoracolumbar during surgery, pedicle screw instrumentation is almost always exclusively used. The choice of using pedicle screw is due to its improved fusion rate and rigidity, compared to its predecessors. It also has other advantages biomechanically. Previously, pedicle screw was used more frequently in lumbar vertebrae compared to other vertebral segments. This was due to reason that the pedicles of lumbar vertebrae are thicker. This makes the process of cannulation becomes easier, it has trajectories that do not breach the important neurovascular structures, and makes it less susceptible to serious neural damage due to medial breach of the screw, because the components of cauda equina are much less prone to damage [1].

In thoracic vertebrae, there is lower margin of error compared to that of the previously mentioned lumbar vertebrae. The

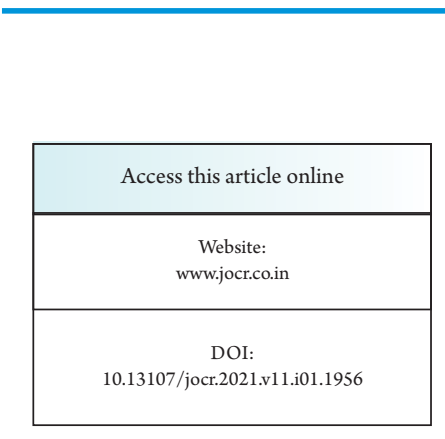

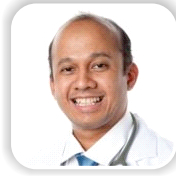

Dr. Didik Librianto

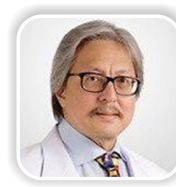

Dr. Ifran Saleh Author's Photo Gallery

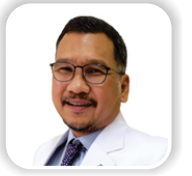

Dr. Fachrisal

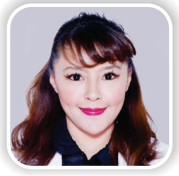

Dr. Widyastuti Srie Utam

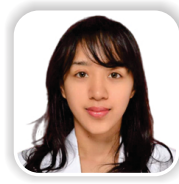

Dr. Witantra Dhamar Hutam

${ }^{1}$ Department of Orthopaedic and Traumatology, Fatmawati Hospital Jl. RS. Fatmawati Raya No.4, Cilandak, Kota Jakarta Selatan, Jakarta, Indonesia,

${ }^{2}$ Department of Orthopaedic and Traumatology, Faculty of Medicine Universitas Indonesia, Cipto Mangunkusumo Hospital, Jl. Pangeran Diponegoro No. 71,

Senen, Kota Jakarta Pusat, Jakarta, Indonesia,

${ }^{3}$ Department of Orthopaedic and Traumatology, Tarakan Hospital, Jl. Kyai Caringin No. 7, Cideng, Kota Jakarta Pusat, Jakarta, Indonesia.

Address of Correspondence:

Dr. Didik Librianto,

Department of Orthopaedic and Traumatology, Fatmawati Hospital, Jl. RS. Fatmawati Raya No.4, Cilandak, Kota Jakarta Selatan, Jakarta 12430, Indonesia. E-mail: didikl.orthopaedic@yahoo.com

Journal of Orthopaedic Case Reports | pISSN 2250-0685 | eISSN 2321-3817 | Available on www.jocr.co.in | doi:10.13107/jocr.2021.v11.i01.1956 This is an Open Access article distributed under the terms of the Creative Commons Attribution Non-Commercial License (http://creativecommons.org/licenses/by-nc/3.0) which permits unrestricted non-commercial use, distribution, and reproduction in any medium, provided the original work is properly cited. 

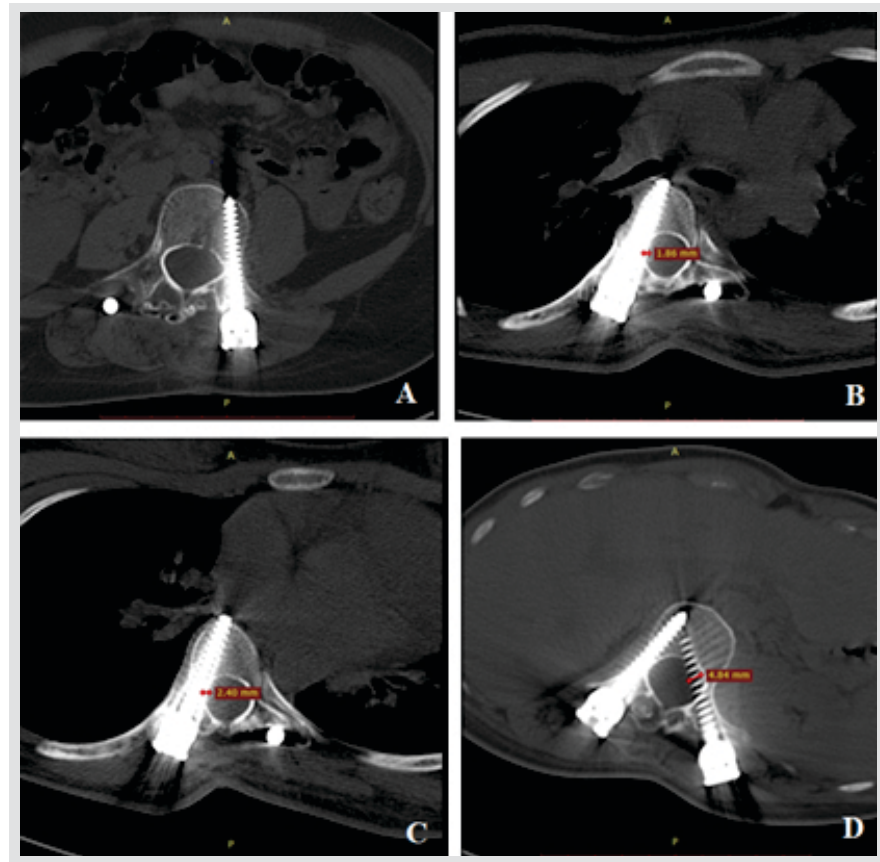

Figure 1: Grading of Medial Breach by Gertzbein Classification. Gertzbein classification classifies the errant screw into four grades: (a) Grade 0 - there is no breach $(0 \mathrm{~mm})$, (b) Grade 1 breach of $<2 \mathrm{~mm}$, (c) Grade 2 - breach of 2 $-4 \mathrm{~mm}$, and (d) Grade 3 - breach of $>4 \mathrm{~mm}$.

medially breached screw is able to injure the spinal cord, whereas the laterally breached screw can injure other structures closely related to the vertebrae. The previous studies showed that the insertion of pedicle screw in thoracic vertebrae was more difficult compared to insertion in lumbar vertebrae, particularly in middle thoracic segment. The reason behind this was that the pedicles in this area are the narrowest. There is also a decreased space between the medial border of the pedicle and spinal cord, making a study concluded that the translational margin of error and the maximal permissible rotational error off the pedicular axis is $1 \mathrm{~mm}$ and 5, respectively [1]. Besides the inherent complexity of the normal anatomy of the thoracic vertebrae, the pre-existent pathologies cause more difficulty in pedicle screw instrumentation. In patients with significant scoliosis, the presence of rotation and asymmetric compression of vertebrae can significantly alter pedicle anatomy, which further complicate the pedicle screw placement [2].

In general, there are four modalities of pedicle screw insertion during spine surgery, they are robot-assisted, computed tomography (CT) navigation-guided, fluoroscopy-assisted, and free-hand techniques. Free-hand technique uses surgeon's appreciation of normal and abnormal spinal anatomy. In this technique, the surgeon entirely depends on pre-operative imaging and intraoperative anatomical landmarks [1]. The previous studies of free-hand technique in the pedicle screw instrumentation in scoliosis showed that free-hand technique is safe [2]. To confirm the safety and accuracy of this free-hand technique, additional study measuring the breach rate of pedicle screw placement in scoliosis is mandatory.
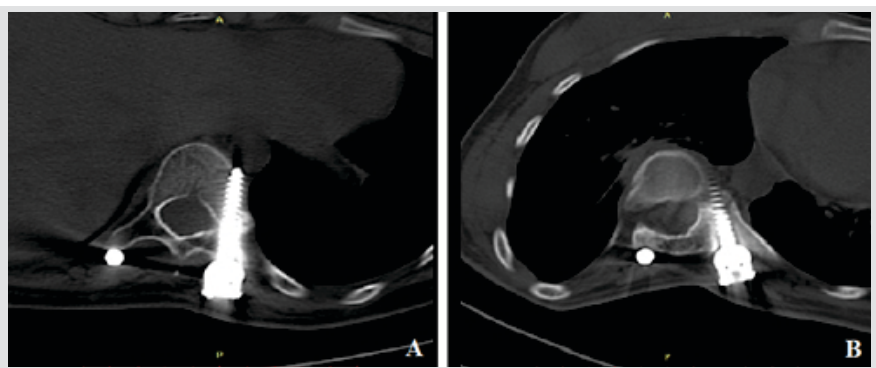

Figure 2: Grading of lateral breach by Heary classification. (a) Grade II and (b) Grade III violation.

We evaluated the breach rate of pedicle screw instrumentation in patient with adolescent idiopathic scoliosis (AIS). We sought the answers to five questions to establish the safety and accuracy of this technique: (1) What is the overall breach rate of pedicle screws instrumentation using free-hand technique? (2) Is there any difference in breach rate between lumbar and thoracic vertebrae? (3) Is the breach rate different for medially and laterally directed screw? (4) What is the breach rate of pedicle screw placement in different levels of the thoracic and lumbar spine? and (5) Is there any difference in breach rate between convex and concave sides?

\section{Materials and Methods}

This was a retrospective study of patients with AIS treated for scoliosis correction in our center from 2017 to 2018. Postoperative computed tomography scan (CT scan) was used to measure the medially and laterally directed screw, and the displacement was graded according to Gertzbein classification (Fig. 1) for medially directed screw. The inferior and superior breaches of pedicle screws were excluded. For laterally directed screw, measurement of screw breach was according to Heary classification (Fig. 2) [3, 4]. Gertzbein classification classifies the breached screw into four grades: Grade 0 - there is no breach $(0 \mathrm{~mm})$, Grade 1 - breach of $<2 \mathrm{~mm}$, Grade 2 - breach of 2-4 $\mathrm{mm}$, and Grade 3 - breach of $>4 \mathrm{~mm}$ [1].

Heary classification used for this study was Heary classification Grade II where screw violates pedicles but screw tip is entirely within the vertebral body and Grade III where the screw tip penetrates lateral body [4]. The study was approved by the Institutional Review Board and informed consent was obtained from all participants. The upper, middle, and lower thoracic spine were defined as thoracic vertebral level of Th1-Th4, Th5-Th8, and Th9-Th12, respectively [5].

All surgeries were performed by the single surgeon (D.L) with over 10 years experience in the treatment of AIS by free-hand technique in Fatmawati General Hospital, Jakarta. Posterior approach with pedicle screw instrumentation using free-hand technique and intraoperative neuromonitoring (IONM) for scoliosis correction was performed in all cases. Breach distance seen in CT scan was measured using Radiant DICOM Viewer ${ }^{\circledast}$ 
software by single examiner (W.D.H) to minimize bias. Statistical analysis was performed using SPSS $^{\circledR}$ Software, and P $<0.05$ was deemed to be statistically significant.

\section{Results}

\section{Patient demographic}

A total of 94 pedicle screws from six female patients with AIS were included in our study. The mean age of the patient is 16.1 years old. No neurologic deficit occurred postoperatively in all patients.

\section{Breach rate analysis}

According to the measurement, overall breach occurred in 31 (33\%) instrumented screws, compared to 63 perfectly placed screws (67\%). Of the breached screws, medial breach occurred in 19 screws (20\%), whereas lateral breach occurred in 12 screws (12\%).

Based on vertebral segments, overall breach in thoracic vertebra occurred in 23 pedicle screws (24.5\%), whereas in lumbar vertebrae, overall breach occurred in 8 pedicle screws ( $8.5 \%)$. This difference in the overall breach rate between thoracic and lumbar vertebrae was not statistically significant $(\mathrm{p}=0.554)$, as shown in Table 1.

\section{Analysis of medial breach}

Medially breached screw was further classified according to Gertzbein classification. Of the overall medially breached screw, 11 (11.6\%) screws fell into Grade 1 violation, 6 (6.3\%) screws fell into Grade 2 violation, and 2 (2.1\%) screws fell into Grade 3 violation. Based on analysis, we did not find a significant difference in the rate of medial breach between thoracic and lumbar vertebrae $(\mathrm{p}=0.711)($ Table 2$)$.

In thoracic vertebrae, medially breached screw occurred in 2 (3\%), 9 (13.6\%), and 3 (4.5\%) screws in upper, middle, and lower thoracic vertebrae, respectively. This finding was statistically significant, in which the overall medially breached screws occurred most commonly in the medial segment of thoracic vertebrae $(\mathrm{P}=0.048)$ (Table 3$)$. About $9.6 \%$ of the medially beached screw occurred as Grade 1 violation, whereas Grade 2 and 3 violations of medially breach screw occurred in $4.3 \%$ and $1.1 \%$ of cases, respectively (Table 3 ).

In lumbar vertebrae, medial breach occurred as Grade 1 violation in two pedicles screws, Grade 2 violation also in two pedicles screws, and Grade 3 violation in one pedicle screw. We assessed the difference of grade of medial breach between thoracic and lumbar vertebrae and found that there was no significant difference in the grade of medial breach between those two segments of vertebrae $(\mathrm{P}=0.762)($ Table 4$)$.

\section{Analysis of lateral breach}

Laterally breached screw was further classified according to Heary classification. Of the overall laterally breached screw, 8 ( $8.51 \%)$ screws fell into Grade II violation and 4 (4.26 \%) screws fell into Grade III violation. Based on analysis, we did not find a significant difference in the rate of lateral breach between thoracic and lumbar vertebrae $(\mathrm{P}=1,000)$ (Table 5).

In thoracic vertebrae, laterally breached screw occurred in 4 (4.1\%), 1 (1.5\%), and 4 (6.1\%) screws in upper, middle, and lower thoracic vertebrae, respectively. This finding showed that there is no statistically significant difference in the rate of lateral breach between segments of vertebrae (Table 6 ). About $6.4 \%$ of the laterally breached screw occurred as Grade II violation, whereas Grade III violations of laterally breach screw occurred 3.2 cases (Table 6).

In lumbar vertebrae, lateral breach occurred as Grade II violation in two pedicles screws and Grade III violation in one pedicle screw. We assessed the difference of grade of lateral breach between thoracic and lumbar vertebrae and found that there was no significant difference in the grade of medial breach between those two segments of vertebrae $(\mathrm{P}=0.927)$ (Table 7$)$.

\section{Breach analysis according to the deformity}

In all analyzed pedicle screws, 49 screws (52.1\%) were inserted in the concave side, whereas 45 screws $(47.9 \%)$ were inserted in the convex side. In the thoracic vertebrae, 36 screws (54.5\%) and 30 screws $(45.5 \%)$ were inserted in concave and convex side of deformity, respectively. In the lumbar vertebrae, 13 screws (46.4\%) were inserted in the concave side and 15 screws (53.6) were inserted in the convex side. We did not find any significant difference in overall breach rate between concave and convex sides of the deformity (Table 8).

According to the analysis, there was statistically significant difference in the rate of medial breach between the concave and convex side, where the risk of medial breach increased 3.049 times in the convex side compared to that in the concave side of the deformity $(P=0.012)$. This was shown by the finding that medial breach occurred in 14 pedicle screws in the convex side, in contrast to only 5 screws in concave side (Table 9).

For the lateral breach, 10 pedicle screws $(10.6 \%)$ occurred in the concave side and 2 pedicle screws $(2.1 \%)$ occurred in the convex side. This finding showed a significant difference in which the risk of lateral breach increased 4.592 times in the concave side compared to that in the convex side of the deformity $(\mathrm{P}=0.021)$ (Table 10). 


\section{Discussion}

In general, there are four modalities of pedicle screw insertion during spine surgery, they are robot-assisted, computed tomography (CT) navigation-guided, fluoroscopy-assisted, and free-hand techniques. A meta-analysis showed that among those four techniques of pedicle screw insertion, there was no statistical difference in the accuracy of the pedicle screw placement. The accuracy for robot-assisted technique was $90.5 \%$, for CT navigation-guided was $95.5 \%$, for fluoroscopicassisted was 91.5\%, and for free-hand technique was 93.1\% [6]. Free-hand technique in the instrumentation of pedicle screw is performed by placing the screw guided by knowledge of anatomical landmark. It is also guided by pre-operative anterior/lateral radiograph and CT scan review. An intraoperative roentgenogram or $\mathrm{C}$-arm image is not used to confirm the correct position of the inserted pedicle screw [7]. This technique is considered to be challenging. However, compared to others, free-hand techniques are less expensive and less complex, with less radiation exposure to both patient and surgeon and less intraoperative time [8]. Moreover, based on previous researches, free-hand technique has an acceptable safety and accuracy [9]. We performed this study to answer five questions regarding the safety and the accuracy of free-hand technique during pedicle screw instrumentation.

Our study showed that breach rate of pedicle screw insertion was $31 \%$, of which, the rate of medial breach was $20 \%$ whereas of lateral breach was $12 \%$. According to previous research, the rate of pedicle screw breach was as high as $39 \%$, with the rate of medial breach of $28 \%$ and lateral breach of $9 \%$ [10]. These values seemed to show a relatively high rate of breach, however, grading of the breach must be considered. As stated before, Gertzbein classification divided the medial breach into three grades. Our study found that most of the medial breach in thoracic vertebrae occurred as Grade 1 violation followed by Grade 2 and Grade 3 violation. Almost similar finding was also encountered in lumbar vertebrae where Grade 1 and Grade 2 violations were more common compared to Grade 3 violation, although these differences in the amount of medially breached screws for each grade in both vertebral segments were not significant (Table 4). The majority of lateral breach found in our study was also as Grade II lateral violation.

Grade 3 violation of medial breach, which occurred in one case for each thoracic and lumbar vertebrae (Fig. 1), was measured to be $5.05 \mathrm{~mm}$ and $4.84 \mathrm{~mm}$, respectively. As reported, there were no neurologic deficits suffered by all patients in this study. This finding is explained by the study performed by Gertzbein et al. [11] which stated that the safe zone of medial encroachment to the spinal canal is $2-4 \mathrm{~mm}$. Four millimeters medial breach is tolerated without injuring the spinal cord or cauda equina, because according to the study in anatomical dissection, there is $2 \mathrm{~mm}$ of epidural space in lumbar vertebrae and additional $2 \mathrm{~mm}$ of subarachnoid space in T10 to L4 vertebrae [12]. Moreover, there is probable spinal canal reserve that not yet been studied. This spinal canal reserves that may explain why in both screws from two patients did not cause neurologic deficit despite medial breach of more than $4 \mathrm{~mm}$.

For lateral breach, violation of the lateral wall of the pedicle in the majority of the cases is not problematic, because the screw is usually secured within the costovertebral articulation [13]. According to the previous researches, the lateral cortex may suffer a breach of up to $6 \mathrm{~mm}$ without causing clinical disturbances. There is also an inherent elasticity to the pedicle of pediatric patients, which can support screws up to $115 \%$ without causing cortical injury [12]. Moreover, researches showed that lateral breach occurred more commonly than medial breach, and most of the lateral breaches were expected as a result of intended juxtapedicular screw placement which did not require screw repositioning [14]. In our study, there were not clinical consequences found caused by laterally breached screw. This might explain the previous theories that lateral breach screw is not a problematic because it is usually secured within the costovertebral articulation when the breach is safe within $6 \mathrm{~mm}$ of breach.

As mentioned before, the lumbar spine has thicker pedicle, making them to be easier to cannulate. They also have trajectories that do not breach important neural or vascular structure, thus, theoretically, the lumbar spine is less susceptible to serious neural damage, particularly of that caused by medial screw violation [1]. The thoracic vertebrae, in other side, have more anatomical variation than lumbar vertebrae. The middle segment of thoracic vertebrae has the narrowest pedicles and decreased space between the medial border of the pedicle and spinal cord [15]. Our study showed that the rate of overall breach, medial breach, and lateral breach did not differ significantly between thoracic and lumbar vertebrae $(\mathrm{P}>0.05)$. However, analysis of medial breach in thoracic vertebrae showed that medial breach was significantly higher in middle thoracic segment compared to that of upper and lower thoracic segments $(P=0.048)$. This finding was explained by a study of Liljenqvist [15] which found that the transverse pedicle width in the middle segment of thoracic vertebrae was significantly smaller. In contrast, we could not find any significant difference in the rate of lateral breach in relation to the segments of thoracic vertebrae.

Scoliotic vertebrae differ substantially to that of normal vertebrae, where the former has asymmetrical intravertebral deformity. In patients with significant scoliosis, the presence of rotation and asymmetric compression of vertebrae can 


\begin{tabular}{|c|c|c|c|c|}
\hline \multirow{2}{*}{ Vertebral segment } & \multicolumn{2}{|c|}{ Breach } & \multirow{2}{*}{$P$ value } & \multirow{2}{*}{ OR $(95 \%$ CI $)$} \\
\hline & Yes $(\%)$ & No $(\%)$ & & \\
\hline Thoracic & $23(24.5)$ & $43(45.7)$ & 0.554 & $\begin{array}{c}1.220 \\
(0.623-2.389)\end{array}$ \\
\hline Lumbar & $8(8.5)$ & $20(21.3)$ & & \\
\hline
\end{tabular}

\begin{tabular}{|c|c|c|c|}
\hline \multirow{2}{*}{ Thoracic segment } & \multicolumn{2}{|c|}{ Medial breach } & \multirow{2}{*}{$P$ value } \\
\hline & Yes & No & \\
\hline Upper segment & $2(3 \%)$ & $18(27.3 \%)$ & \multirow{3}{*}{0.048} \\
\hline Medial segment & $9(13.6 \%)$ & $15(22.7 \%)$ & \\
\hline Lower segment & $3(4.5 \%)$ & $19(28.8 \%)$ & \\
\hline
\end{tabular}

Table 5: Rate of lateral breach between thoracic and lumbar vertebrae

\begin{tabular}{|c|c|c|c|c|}
\hline \multirow{2}{*}{ Vertebral segment } & \multicolumn{2}{|c|}{ Lateral breach } & \multirow{2}{*}{$\boldsymbol{P}$ value } & OR (95\% CI) \\
\cline { 2 - 5 } Thoracic & Yes & No & & 1,273 \\
Lumbar & $9(9.6 \%)$ & $\begin{array}{c}527 \\
(60.6 \%)\end{array}$ & 1,000 & $(0.372-4.353)$ \\
\hline
\end{tabular}

Table 2: Rate of medial breach between thoracic and lumbar vertebrae

\begin{tabular}{|c|c|c|c|c|}
\hline \multirow{2}{*}{ Vertebral segment } & \multicolumn{2}{|c|}{ Medial breach } & \multirow{2}{*}{$\boldsymbol{P}$ value } & OR (95\% CI) \\
\cline { 2 - 5 } & Yes & No & & 1.188 \\
Thoracic & $14(14.9 \%)$ & $52(55.3 \%)$ & 0.711 & $(0.473-2.982)$
\end{tabular}

Table 4: Grade of medial screw between thoracic and lumbar vertebrae

\begin{tabular}{|c|c|c|c|}
\hline \multirow{2}{*}{ Grade of medial breach } & \multicolumn{2}{|c|}{ Vertebral segment } & \multirow{2}{*}{$\boldsymbol{P}$ value } \\
\cline { 1 - 3 } & Thoracic & Lumbar & \\
Grade 0 & $52(55.3 \%)$ & $23(24.5 \%)$ & \\
Grade 1 & $9(9.6 \%)$ & $2(2.1 \%)$ & 0.762 \\
Grade 2 & $4(4.3 \%)$ & $2(2.1 \%)$ & \\
Grade 3 & $1(1.1 \%)$ & $1(1.1 \%)$ & \\
\hline
\end{tabular}

\begin{tabular}{|c|c|c|c|}
\hline \multirow{2}{*}{ Thoracic segment } & \multicolumn{2}{|c|}{ Lateral breach } & \multirow{2}{*}{$P$ value } \\
\hline & Yes & No & \\
\hline Upper & $4(6.1 \%)$ & $16(24.2 \%)$ & 0.234 \\
\hline Medial & $1(1.5 \%)$ & $23(34.8 \%)$ & \\
\hline Lower & $4(6.1 \%)$ & $18(27.3 \%)$ & \\
\hline
\end{tabular}

\begin{tabular}{|c|c|c|c|c|c|}
\hline \multicolumn{5}{|c|}{$\begin{array}{l}\text { Table 7: Grade of lateral screw between thoracic and } \\
\text { lumbar vertebrae }\end{array}$} & \\
\hline \multirow{2}{*}{\multicolumn{2}{|c|}{ Grade lateral breach }} & \multicolumn{2}{|c|}{ Segment vertebrae } & \multirow{2}{*}{$\boldsymbol{P}$} & \\
\hline & & Thoracic & Lumbar & & \\
\hline \multicolumn{2}{|c|}{ Grade 0} & $57(60.6 \%)$ & $25(26.6 \%)$ & \multirow{3}{*}{0.927} & \\
\hline \multirow{2}{*}{\multicolumn{2}{|c|}{$\begin{array}{l}\text { Grade } 2 \\
\text { Grade } 3 \\
\end{array}$}} & $6(6.4 \%)$ & $2(2.1 \%)$ & & \\
\hline & & $3(3.2 \%)$ & $1(1.1 \%)$ & & \\
\hline \multicolumn{6}{|c|}{$\begin{array}{l}\text { Table 9: Analysis of the medial breach according to the side } \\
\text { of deformity }\end{array}$} \\
\hline & \multicolumn{2}{|c|}{ Medial breach } & P valu & \multirow{2}{*}{\multicolumn{2}{|c|}{ OR $(95 \%$ CI $)$}} \\
\hline & Yes & No & $P$ value & & \\
\hline Convex & 14 & 31 & 0.012 & $\begin{array}{r}3.049 \\
(1.194-7\end{array}$ & \\
\hline Concave & 5 & 44 & & & \\
\hline
\end{tabular}

significantly alter pedicle anatomy and complicate pedicle screw placement. The endosteal width of the pedicle in the concave side of the deformity is smaller than in the convex side of the deformity [15]. Our analysis of the influence of the side of deformity to the overall breach rate showed that there is no difference in the overall breach rate between concave and convex side of the deformity. Our finding is in accordance with the finding by Min et al. [16] which found that the concave and convex side of the deformity had similar rate of breach. However, when we analyzed medial and lateral breach individually, we found that each concave and convex side of the deformity carried risk of screw breach. The risk of medial breach
Table 8: Analysis of overall breaching rate according to the side of deformity

\begin{tabular}{|c|c|c|c|c|}
\hline \multirow{2}{*}{ Side } & \multicolumn{2}{|c|}{ Breaching } & \multirow{2}{*}{$\begin{array}{l}P \text { (Chi- } \\
\text { square) }\end{array}$} & \multirow{2}{*}{ OR $(95 \%$ CI $)$} \\
\hline & Yes & No & & \\
\hline & $15(16 \%)$ & $34(36.2 \%)$ & 0.611 & $\begin{array}{c}0.861 \\
(0.484-1.532)\end{array}$ \\
\hline Convex & $16(17 \%)$ & $29(30.9 \%)$ & & \\
\hline
\end{tabular}

Table 10: Analysis of the lateral breach according to the side of deformity

\begin{tabular}{||c|c|c|c|c|}
\hline & \multicolumn{2}{|c|}{ Lateral breach } & P value & OR (95\% CI) \\
\hline & Yes & No & & \\
\hline Concave & 10 & $39(41.5 \%)$ & 0.021 & 4.592 \\
& $(10.61 \%)$ & & & \\
\hline Convex & $2(2.1 \%)$ & $43(45.7 \%)$ & & \\
\hline
\end{tabular}

was increased 3 times in the convex side of the deformity, whereas the risk of lateral breach was increased 4.6 times in the concave side of the deformity $(\mathrm{P}<0.05)$. This means that if a pedicle screw is to be inserted in the convex side, when the breaching is to be happen, medial breach is the probable result. The same also applied in the concave side, where the lateral breach is the probable result if the breaching is going to happen.

Literatures showed that instrumentation of pedicle screw placement on concave side of AIS is known to be more difficult than that of convex side screw instrumentation. The placement of the convex screws is technically easier than that of the concave side because of anatomical easiness to find the entry 
point of pedicle, less variation of pedicle morphology, and bigger size of the pedicle width. However, insertion of the convex screw may be more dangerous than insertion of the concave one, because if the surgeon uses routine medial angulation, the screw will be directed into the spinal canal, creating medial breach [16]. This may explain our finding of why the risk of medial breach is higher in the convex side of the deformity. Smorgick et al. [17] in their study found that the majority of the breach occurred as lateral breach in the concave side, this was due to structural advantage of the thicker medial pedicle wall compared to the lateral pedicle cortex. This finding may also explain our finding on why concave side of the deformity increased the risk of lateral breach.

\section{Conclusion}

Our study enabled us to answer five questions arisen previously. The overall breach rate using free-hand technique was $31 \%$, however, the majority of the breach is low-grade breach within the safe zone. There was no difference in the overall, medial, and lateral breach rate between lumbar and thoracic vertebrae, but there was significantly higher medial breach in the middle thoracic segment. There was no significant difference in overall breach rate between thoracic and lumbar vertebrae. Risk of medial breach was 3 times higher in the convex side of deformity, whereas risk of lateral breach was 4.6 times higher in the concave side of the deformity. Our study found that freehand technique is safe and effective method of pedicle screw instrumentation for correction of AIS. Some inherent factors may influence the risk of pedicle screw breach; therefore, careful measure should be taken to address the issues.

\section{Clinical Message}

- Free-hand technique is safe and effective method of pedicle screw instrumentation for correction of AIS (adolescent idiopathic scoliosis).

- Some inherent factors may influence the risk of pedicle screw breach either medially and laterally, therefore, careful measure should be taken to address the issues.

\section{References}

1. Puvanesarajah V, Liauw JA, Lo SF, Lina IA, Witham TF. Techniques and accuracy of thoracolumbar pedicle screw placement. World J Orthop 2014;5:112-23.

2. Modi HN, Suh SW, Hong JY, Yang JH. Accuracy of thoracic pedicle screw using ideal pedicle entry point in severe scoliosis. Clin Orthop Relat Res 2010;468:1830-7.

3. Rajasekaran S, Bhushan M, Aiyer S, Kanna R, Shetty AP. Accuracy of pedicle screw insertion by AIRO ${ }^{-}$ intraoperative $\mathrm{CT}$ in complex spinal deformity assessed by a new classification based on technical complexity of screw insertion. Eur Spine J 2018;27:2339-47.

4. Cordemans V, Kaminski L, Banse X, Francq BG, Detrembleur $\mathrm{C}$, Cartiaux O. Pedicle screw insertion accuracy in terms of breach and reposition using a new intraoperative cone beam computed tomography imaging technique and evaluation of the factors associated with these parameters of accuracy: A series of 695 screws. Eur Spine J 2017;26:2917-26.

5. Yoon SH, Kim WH, Chung SB, Jin YJ, Park KW, Lee JW, et al. Clinical analysis of thoracic ossified ligamentum flavum without ventral compressive lesion. Eur Spine J 2011;20:216-23.

6. Perdomo-Pantoja A, Ishida W, Zygourakis C, Holmes C, Iyer RR, Cottrill E, et al. Accuracy of current techniques for placement of pedicle screws in the spine: A comprehensive systematic review and meta-analysis of 51,161 screws. World Neurosurg 2019;126:664-78.

7. Karapinar L, Erel N, Ozturk H, Altay T, Kaya A. Pedicle screw placement with a free hand technique in thoracolumbar spine: Is it safe? J Spinal Disord Tech 2008;21:63-7.

8. Motiei-Langroudi R, Sadeghian H. Assessment of pedicle screw placement accuracy in thoracolumbosacral spine using freehand technique aided by lateral fluoroscopy: Results of postoperative computed tomography in 114 patients. Spine J 2015; 15:700-4.

9. Vijayeswaran N, Venkatesh R, Murugesan G, Balamurugan S, Indunesh K, Pradeep TT. Is freehand technique of pedicle screw insertion in thoracolumbar spine safe and accurate? Assessment of 250 screws. J Neurosci Rural Pract 2019; 10:256-60.

10. Castro W, Halm H, Jerosch J, Malems J. Accuracy of pedicle screw placement in lumbar vertebrae. Spine (Phila $\mathrm{Pa}$ 1976) 1996;21:1320-4.

11. Gertzbein SD, Robbins SE. Accuracy of pedicular screw placement in vivo. Spine (Phila Pa 1976) 1990;15:11-4.

12. Galindo $\mathrm{MH}$, Galindo RH, Medeiros RC, Pereira AF, Ferreira MA, Rangel TD. Misplaced pedicle screws by the freehand technique: What is the real value for the occurrence of neurological lesions? Coluna/Columna 2013;12:315-8. 
13. Kim YJ, Lenke LG, Bridwell KH, Cho YS, Riew KD. Free hand pedicle screw placement in the thoracic spine: Is it safe? Spine (Phila Pa 1976) 2004;29:333-42.

14. Tan LA, Yerneni K, Tuchman A, Li XJ, Cerpa M, Lehman RA Jr., et al. Utilization of the 3D-printed spine model for freehand pedicle screw placement in complex spinal deformity correction.J Spine Surg 2018;4:319-27.

15. Liljenqvist $U$, Hackenberg L. Morphometric analysis of thoracic and lumbar vertebrae in idiopathic scoliosis. Stud Health Technol Inform 2002;88:382-6.
16. Min WK, Na SB, JangJA. Accuracy of thoracic pedicle screw placement using freehand technique and triggered EMG in adolescent idiopathic scoliosis: Is it different between concave and convex side? J Orthop Surg (Hong Kong) 2018;26:2309499018784975.

17. Smorgick Y, Millgram MA, Anekstein Y, Floman Y, Mirovsky Y. Accuracy and safety of thoracic pedicle screw placement in spinal deformities. J Spinal Disord Tech 2005; 18:522-6.
Conflict of Interest: Nil

Source of Support: Nil

Consent: The authors confirm that informed consent was obtained from the patient for publication of this case report

\section{How to Cite this Article}

Librianto D, Saleh I, Fachrisal, Utami WS, Hutami WD. Breach Rate Analysis of Pedicle Screw Instrumentation using Free-Hand Technique in the Surgical Correction of Adolescent Idiopathic Scoliosis. Journal of Orthopaedic Case Reports 2021 January; 11(1):38-44. 